\title{
Función de las Innovaciones Estilísticas en Rayuela
}

Todo análisis de la prosa de esa caja de Pandora que es Rayuela - por seguir la denominación de Carlos Fuentes- tiene que partir forzosamente de las 21 líneas —una página escasa- del capítulo 68. Emplea Cortázar en el mismo tres tipos de vocablos. El primero -el menos significativo- consta de palabras de significado conocido dado su uso frecuente incluso a nivel conversacional; quedan encuadradas en él no sólo las partículas, conjunciones, preposiciones, etc., sino también verbos, sustantivos y adjetivos (agolpar, caer, procurar, sentir... principio, momento, cresta, ... salvaje, profundo, cruel...).

Un segundo grupo de palabras son sólo semiconocidas por el lector. Se trata de vocablos compuestos en que la yuxtaposición de cada uno de los elementos y a veces uno de los términos o ambos, son creación del autor:

$\begin{array}{lll}\text { hidtomurias } & \text { incopelusas } & \text { cariaconcia } \\ \text { ulucordio } & \text { jadehollante } & \text { embocapluvia } \\ \text { sobrehumitica } & \text { agopausa } & \text { volposados } \\ \text { balparamar } & \text { marioplumas } & \text { ordopena }\end{array}$

En el primero de los términos la labor del autor se limita a unir las partes "hidro" y "muria" (cercado de piedras para marcar un terreno). En "cariconcia" trata solamente de formar un substantivo tomándolo del adjetivo cariacontecido. "Jadehollante" es un calco fónico de jadeante. "Sobrehumítica" es una construcción montada sobre el adjetivo "sobrehumana". El segundo término "humítica" es un claro cultismo del autor; humus equivale en latin a tierra; de ahí que sobrehumítica signifique supraterrena.

Hay, por último, una serie de palabras de acuñación exclusiva del 
novelista, que en gran parte no vuelven a aparecer en la obra. Los ejemplos aquí son más numerosos:

$\begin{array}{lll}\text { amalar } & \text { noema } & \text { clémiso } \\ \text { ambonio } & \text { sústalo } & \text { grimado } \\ \text { envulsionar } & \text { nóvalo } \\ \text { relamar } & \text { espejunar } & \text { trimalciato } \\ \text { arnillas } & \text { fílulas } & \text { tordular } \\ \text { ergomanina } & \text { orfelunio } & \text { encrestoriar } \\ \text { hurgalio } & \text { esterfurosa } & \text { convulcante } \\ \text { clinón } & \text { orgumio } & \text { esproemios } \\ \text { mátricas } & \text { márulo } & \text { troc } \\ \text { merpasmo } & \text { pínice } & \text { niolama } \\ \text { resolvirar } & \text { carinias } & \text { gunfias } \\ \text { argutendida } & & \end{array}$

Unicamente el primer término "amalar" figura en el Diccionatrio de la lengua si bien como palabra ya en desuso por "malear".

Lo más significativo del pasaje es que éste cobra sentido a pesar del número tan considerable de términos desconocidos. Cortázar no precisa aclararnos previamente de qué se trata como lo había hecho en otro capítulo anterior (p. 104), donde utiliza el mismo procedimiento de acumulación dé neologismos, si bien a nivel más reducido: (El término "gunfia" aparece también alli). En el capítulo que comentamos - 68- Cortázar alude a una relación física amorosa. El juego de pronombres - "apenas él le amalaba el noema, a ella se le agolpaba el clémiso"- del comienzo nos pone en antecedentes. Después se trata ya de alusiones cuyo sentido no es difícil de adivinar. El término "muria" señala el apartamiento de la pareja, "relamar". se relaciona fácilmente con relamer, "envulsionar" con convulsión, "tordular" con retorcer, "encrestoriar", "entreplumar" y "extrayuxtar" señalan los movimientos periódicos de penetración y abandono del acto amoroso. En el campo de los sustantivos las referencias son más concretas. "Mátricas" alude al aparato genital femenino, "carinia" es el término "caricia" ligeramente retocado; "orgumio y mespasmo" recuetdan al lector el término "orgasmo". Palabras como "clinón" y "cresta" están señalando el mismo momento de efusión amorosa. Eso sin contar las dos interjecciones "Evohé, evohé" que marcan igualmente el momento culminante del acto. .

La estructura melódica de la página responde igualmente al ritmo expresado. El momento culminante de ese efecto viene dado antés de 
las significativas interjecciones ya indicadas por un amontonamiento precipitado de verbos, sustantivos $y$ adjetivos.

Apenas se entreplumaban, algo como un ulucordio los encrestoriaba, los extrayuxtaba y paramovía, de pronto era el clinón, la esteffurosa convulcante de las mátricas, la jadehollante embocapluvia del orgumio, los esproemios del merpasmo en una sobrehumítica agopausa.

El final, a efectos rítmicos, es un claro anticlímax. La ruptura de Cortázar con la convención no es radical, como puede verse en este capítulo. El novelista ha llegado probablemente al límite de las posibilidades en este sentido, a sus fronteras que vienen dadas nada menos que por el carácter inmutable del signo lingüístico a nivel individual, como señaló Saussure en su día. Un examen detenido de las palabras utilizadas, por el novelista nos lleva a la conclusión de que en muchos casos, no se trata de creaciones ex-nihilo. $Y$ no aludo sólo a los ejemplos ya citados de vocablos que evocan palabras de sobra conocidas, sino al carácter unitario de todo el fragmento, en el que cada miembro cobra pleno sentido en oposición contrastante con el resto.

La búsqueda de nuevas vías estilísticas no se reduce, en Rayuela, al capítulo que comento. Es un intento general. Hay en la obra un pasaje altamente significativo al respecto. Es una moreliana en donde se aboga por una actitud de ruptura con los moldes expresivos tradicionales:

Estoy revisando un relato que quisiera lo menos literario posible. Empresa desesperada desde el vamos, en la revisión saltan enseguida las frases insoportables. Un personaje llega a una escalera: "Ramón emprendió el descenso" ... Tacho y escribo: "Ramón empezó a bajar. (p. 538). ${ }^{1}$

En otro lugar Cortázar alude a "una lengua hecha de frases preacuñadas para transmitir ideas archipodridas" (p. 227) dentro de la

1 Todas las citas se hacen por la $2^{\text {a }}$ ed. de Rayuela (Buenos Aires: Editorial Sudamericana, 1965). Compárese, por el paralelismo de ambas actitudes, con el siguiente fragmento de Juan de Mairena de Antonio Machado:

- Señor Pérez, salga Ud. a la pizarra y escriba: "Los eventos consuetudinarios que acontecen en la rúa."

EI alumno escribe lo que se le dicta.

-Vaya Ud. poniendo eso en lenguaje poético.

El alumno, después de meditar, responde: "Lo que pasa en la calle".

Mairena: No está mal. De Obras, poesia y prosa (Buenos Aires, 1964); p. 351. 
misma actitud de repulsa del "bello estilo" (p. 103). Este deseo de echar por la borda el estilo envarado se pone de manifiesto en la crítica del diálogo antinatural:

Imaginando falsedades. . Hablás como en los diálogos de las mejores novelas rioplatenses. Ahora solamente te falta reirte con todas las visceras de mi grotesqueria sin pareja, y la rematás fenómeno (p. 100).

Como prototipo del mismo, el autor reproduce, en el capítulo 41, uno entablado por dos españoles, López y Pérez.

Dentro de este contexto de rechazo de toda pretensión purista cabe entender el juicio negativo que le merece el Diccionario de la Real Academia de la Lengua: "Es realmente la necrópolis... No sé cómo le dura la encuadernación" (p. 279). Una de las razones que le mueven a darle ese calificativo es el no haber encontrado en el mismo una palabra tan de uso corriente como "joder".

La jitanjáfora - puro elemento fónico- es el desafío más atrevici. a una sbra lexicográfica en que se registra la fuerza significativa a cada vocablo:

\section{$\mathrm{U} \mathrm{Nu}$ \\ U Tin}

$\mathrm{Mya} \mathrm{Bu}$,

Thado Thiri Thudama U E Maung,

Sithu U Cho

Wunna Kyaw Htin U Khin Zaw

Wunna Kyaw Htin U Thein Han

Wunna Kyaw Htin U Myo Min

Thiri Pyanchi U Thant,

Thado Maha Thray Sithu U Chan Htoon. (p. 280). ${ }^{2}$

A este deseo de ruptura de normas previas responden las renovaciones ortográficas que de vez en cuando se observan en la obra. El capitulo 69, el más conocido a este respecto, está redactado siguiendo

2 Si se examina con detenimiento, se observan dos claras alusiones, la de U Cho Min y la de U Thant. Alfonso Reyes, gran conocedor de la problemática de las jitanjäforas, puso de manifiesto la ruptura de las mismas con los esquemas lógicos: "Un poco de jitanjáforas no nos viene mal para devolver a la palabra sus captaciones alógicas..." (Obras Completas, México: Fondo de Cultura Económica, 1962), vol: XIV, p. 198. 
una ortografía puramente fonética. La $c$ desaparece (notisia/asendido); no se diferencia la $b$ de la $v$ (se escribe siempre aquélla salvo en Renovigo, caso por cierto sintomático, título de la revista que postula un cambio en este sentido; bida/barias); la $\mathrm{y}$ aparece en lugar de 11; la $h$ no se transcribe. "Tubo un alto konsepto de la lealtad i fue asta el kampo de bataya." (p.429).

A idéntico deseo de liberación responde la frecuente inclusión de vocablos o frases en otro idioma: "Complejo de la Arcadia, retorno al gran útero, back to Adam, le bon sauvage" (p. 432).

En muchas ocasiones se trata de fragmentos de letras de canciones:

Desvalida, se le ocurrian pensamientos sublimes, citas de poemas que se apropiaba para sentirse en el corazón mismo de la alcachofa por un lado I ain't got nobody, and nobody cares for me, que no era cierto ya que por lo menos dos de los presentes estaban. malhumorados por causa de ella, $\mathrm{y}$ al mismo tiempo un verso de Perse, algo así como Tu est là, mon amour, et je n'ai lieu qu'en toi, donde la Maga se refugiaba..." (p. 81).

Otras se trata de reproducir las palabras de un nativo: "Al otro día aparece Etienne, y todavía con la boina en la mano, Dis donc, c'est épatant ça! y levanta a la lámpara..." (p. 461). O de plasmar un diálogo entre personajes que se expresan en distinta lengua:

\section{Alguno que saque el yesquero,}

Babs

coño. Tu pourrais quand même parler français, non? Ton copain l'argencul n'est pas là pur piger ton cha-

Ronald rabia. Un fósforo, Ronald. Maldita llave, se ha

Etienne herrumbrado, el viejo la guardaba dentro de un va-

Etienne so con agua. Mon copain, mon copain. No creo que venga. No lo conocés. Mejor que vos. Qué va.

Perico Wanna bet something? Ah, merde, mais c'est la tour

Ronald de Babel, ma parole. (p. 493).

En una ocasión la cita de un idioma extranjero - sueco- tiene tan sólo un sentido burlesco: "Trata de cosas tales como la Menthalhygieniska synpunkter i förskoleundervisning" ( $\mathrm{p}$. 285).

Esta inclusión de elementos extraños en el texto castellano -que sería objeto de más de una agria nota censora por parte de la ortodoxia- nos pone de manifiesto a qué grado de "impureza" llega la 
prosa de Cortázar. Resultaría ingenuo pensar que con tal actitud el novelista persigue facilitar su tarea o justificar su abandono. Hay un pasaje donde se.pone de manifiesto la cuidadosa detención de que es objeto este problema: Hace rato que no me acuesto con las palabras. Las sigo usando, como vos y como todos, pero. las cepillo muchísimo antes de ponérmelas" (p. 115).

La lección estilística de Rayuela no es fruto del azar. Tampoco se trata de un juego intrascendente. El título de la obra - "Rayuela"y algunos pasajes al parecer gratuitos de la misma han contribuido a dar la impresión de su superficialidad, falsa por. cierto. Porque desde el primer capítulo - las primeras palabras- se nos habla de una búsqueda problemática. "¿Encontraría a la Maga?". El sobrenombre de la mujer que aparece en la primera parte junto a Oliveira no es casual. Lucía - tal es el verdadero nombre de la Maga (Cfr. p. 95 entre otras) es el prototipo de personaje libre de trabas intelectuales, capaz de fu-; sionarse directamente con lo que ve, de entrar en comunión con lo que vive, sin precisar intermedios lógicos que le vayan dando una razón de cada una de las vivencias que la distancian de las mismas:

-Parto del principio de que la reflexión debe preceder a la acción, bobalina.

- - Partís del principio, dijo -la Maga. Qué complicado. Vos sos como un testigo, sos el que va al museo y mira los cuadros. Quièró decir que los cuadros están ahí y vos en el museo, cerca y lejos al mismo tiempo. Yo soy un cuadro... Vos creés que estás en esta pieza, pero no estás. Vos está mirando la pieza, no estás en la pieza. (p. 34). tenido:

En otro pasaje se insiste en el mismo motivo de un modo más de-

¿Peto no hemos vivido así todo el tiempo lacerándonos dulçemente? No, no hemos vivido asi, ella hubiera querido pero una vez más yo volví a sentar el falso orden que disimula el caos, a fingir que me entregaba a una vida profunda de la que sólo tocaba el agua terrible con la punta del pie. Hay ríos metafísicos, ella los nada como esa golondrina está nadando en el aire, girando. alucinada en torno al campanario, dejándose caer para levantarse mejor con el impulso. Yo describo y defino y deseo esos ríos. Ella los nada. Yo los busco, los encuentro, los miro desde el puente, 
ella los nada. $Y$ no lo sabe, igualita a la golondrina. No necesita saber como yo, puede vivir en el desorden sin que ninguna conciencia de orden la retenga. Ese desorden que es su orden misterioso, esa bohemia del cuerpo y el alma que le abre de par en par las verdaderas puertas. Su vida no es desorden más que para mí, enterrado en prejuicios que desprecio y respeto al mismo tiempo. Yo, condenado a ser absuelto irremediablemente por la Maga que me juzga sin saberlo. Ah, dẻjame entrar, déjame ver algún día cómo ven tus ojos (p. 116).

El intento de relación con la Maga es, desde el punto de vista de Horacio, una tentativa de renovación de los esquemas ético-morales, como Gabriela de Sola ha apuntado. ${ }^{3}$ El amor a través de la pareja humana - es vía de unidad y comunión con el ser total de la humanidad. La Maga es un medio de acceso a lo extralógico - como ya se ha visto. Los ataques a las construcciones intelectuales rígidas son constantes: "Todo se encadena perfectamente si a uno se le da realmente la gana. Lo único falso en esto es el análisis" (p. 289). La explicación de tal actitud es clara:

La razón sólo nos sirve para disecar la realidad en calma, o analizar sus futuras tormentas, nunca para resolver una crisis instantánea. Pero esas crisis son como mostraciones metafísicas, che, un estado que quizá, si no hubiéramos agarrado por la vía de la razón, sería el estado natural y corriente del pitecántropo erecto (p. 196).

Lo que el entendimiento pretende con sus razonamientos cuadriculados es ocultar la falta de sentido de la existencia:

$\mathrm{Y}$ esas crisis que la mayoría de la gente considera como escandalosas, como absurdas, yo personalmente tengo la impresión de que sirven para mostrar el verdadero absurdo, el de un mundo ordenado y en calma, con una pieza donde diversos tipos toman café a las dos de la mañana, sin que realmente nada de eso tenga el menor sentido como no sea el hedónico, lo bien que estamos al lado de esta estufita que tira tan meritoriamente. Los milagros nunca me han parecido absurdos; lo absurdo es lo que los precede $y$ sigue (p. 196).

3 Graciela de Sola, Julio Cortazar y el bombre nuevo. (Buenos Aires, 1968), p. 110 , 
Se trata de intentar otro camino, como dice Oliveira tras definir magistralmente lo que a su juicio es el absurdo.*

- Renunciando a la inteligencia?. .

-No sé, tal vez. Empleándola de otra manera. Estará bien probado que los principios lógicos son carne y uña con nuestra inteligencia? Si hay pueblos capaces de sobrevivir dentro de un orden mágico. ... Cierto que los pobres comen gusanos crudos, pero eso también es una cuestión de valores (pp. 197-8).

Dentro de este contexto hay que explicar las continuas referencias musicales - jazz sobre todo, tango en segundo plano- de la novela.

De nuevo se trata de escapar a una interpretación lógica del mundo —"Eh, Cartesius, viejo jodido"- (p. 91) e intentar aprehenderlo por otra vía más intuitiva:

.. de los show boats y de las noches de Storyville habia nacido la única música universal del siglo, algo que acercaba a los hombres más y mejor que el esperanto, la Unesco o las aerolíneas, una música bastante primitiva para alcanzar universalidad y bastante buena para hacer su propia historia... el jazz es como un pájaro que migra. . salta batreras, es la lluvia y el pan y la sal, algo absolutamente indiferente a los ritos nacionales, a las tradiciones inviolables, al idioma y al folklore: una nube sin fronteras, un espia del aire y del agua, una forma arquetípica, algo de antes, de abajo, que reconcilia mexicanos con noruegos y rusos y españoles, los reincorpora al oscuro fuego central olvidado, torpe y mal y precariamente los devuelve a un origen traicionado, les señala que quizá había otros caminos dulces de caminar y que no los tomaron... (p.88).

Es una vía que rompe con la lo(gi)ca, como certeramente la denomina Oliveira. La mística puede ser un camino. Significativamente el capítulo 70 es un fragmento de Eckhardt: La aparente inconsistencia del capítulo 41 - una de las cumbres de la novela latinoamericana de todos los tiempos-, el transporte de clavos y mate a cargo de Talita o la ocupación circense de la segunda parte cobran a esta luz una

4 "El absurdo es que no parezca un absurdo - dijo sibilinamente Oliveira. El absurdo es que salgas por la mañana a la puerta y encuentres la botella de leche en el umbral y te quedes tan tranquilo porque ayer te pasó lo mismo y mañana te volverá a pasar. Es ese estancamiento, ese así sea, esa sospechosa carencia de excepciones." (p. 197). 
nueva dimensión. No se trata ya de actividades gratuitas. La única manera de romper la falta de sentido cuanto nos rodea es dedicarse a actividades igualmente carentes de significado:

En el fondo podríamos ser como en la superficie, pensó Oliveira, pero habría que vivir de otra manera. ¿Y qué quiere decir vivir de otra manera? Quizá vivir absurdamente para acabar con el absurdo, tirarse en sí mismo con una tal violencia que el salto acabara en los brazos de otro (p. 120).

El absurdo cobraría asi un sentido, por paradójico que parezca. ${ }^{5}$ Dentro de esta perspectiva hay que situar las renovaciones de Cortázar en el terreno del estilo. A su actitud iconoclasta de clichés archirrepetidos, de rígidos moldes mentales, a su indagación - permítaseme por una vez la dicotomía - de fondo, tiene que responder una forma también que haga tábula rasa de las experiencias anteriores. $\mathrm{Y}$ el relativo fracaso en cuanto a resultados se refiere de ese intento de captación del universo por una vía extraintelectual, o si se desea por una vía intelectual y no de acuerdo con los caminos trillados, tiene su correlato en el carácter esporádico del experimento estilistico. Escribir las 635 páginas de Rayuela en el mismo tono del capítulo 68 habría sido imposible. Porque el escritor no puede escoger su estilo en una especie de arsenal intemporal de formas literarias. El carácter ambiguo de la escritura -agudamente señalado por Roland Barthes en Le degré zéro de l'écriture se pone de manifiesto en el hecho de que:

.. d'une part, elle nait incontestablement d'une confrontation de l'écrivain et de sa societé; d'autre part, de cette finalité sociale, elle renvoie l'écrivain, par une sorte de transfert tragique, aux sources instrumentales de sa création" (op. cit. p. 27).

Sería con todo injusto partir de estas limitaciones intrinsecas al hecho mismo de tomar la pluma -además de la relativa a la inmutabilidad, ya indicada- del signo linguístico a nivel individual, para restar importancia a las innovaciones del autor. En el forcejeo dialéctico entre formas heredadas de la tradición e intervención de la personalidad creadora son muchos los grados y matices. Cortázar ha llegado en este sen-

5 Cfr. en otro campo y a modo de ilustración paralela las luminosas explicaciones de Martín Esslin en El teatro del absutdo, sobre todo el capitulo VII, "El sentido del absurdo" (p. 309 y siguientes. Cito por la edición alemana, Hamburgo, 1971). 
tido en Rayuela - ya se ha señalado- a un punto difícil de alcanzar; y es propio calificar de revolucionaria la intención y factura de la obra, como lo ha hecho Gabriela de Sola. ${ }^{6}$

En las obras posteriores Cortázar no ha sido capaz de superarse en este aspecto. La vuelta al dia en ochenta mundos (1967) y Ultimo round (1969) suponen una ruptura con los aspectos externos de la obra escrita, que en parte - de un modo discreto si se quiere, pero real- aparecía ya en Rayuela. Por ejemplo, en el capítulo 34 de la misma se desarrollan dos temas distintos cuya lectura se tiene que llevar a cabo exclusivamente a base de las líneas pares o impares pero no de un modo normal e ininterrumpido. La inclusión de un poema de Octavio Paz (de Salmandra) en el capitulo 149 o las citas de periódicos (capítulos $130 / 150 \ldots$ ) o de autores (capítulos 126/128) serían también un precedente de la dispersión y variedad de las dos obras citadas, donde se combinan reportajes, textos del diario del Che Guevara, pasquines de los acontecimientos de Mayo de 1968 en Patís, poemas, fotografías y fragmentos de crítica literaria (por ejemplo, un certero estudio sobre Lezama Lima en La vuelta al día) o sobre la imposibilidad de la literatura hispana e hispanoamericana de escribir pornografía.

Se trata, con todo, de innovaciones más bien superficiales. Al leçtor que toma en sus manos Ultimo round, la obra más atrevida en este aspecto, le puede llamar a engaño la transformación exterior de la obra. Porque de hecho los cambios son - sobre todo al menos, ya que no exclusivamente- de carácter tipográfico. Una razón mảs en apoyo del carácter de barrera crítica difícilmente transitable, de la experiencia de Rayuela.

\section{A. Carlos isasi angulo}

\section{Der Universtät Exlangen, Nïrembert West Germany.}

6 Op. cit.; p. 87. En el mismo sentido se expresa Carlos. Fuentes en La nueva novela bispanoamericana (México: Cuadernos de Joaquín Mortiz, 1969, PP. 67-77). 